\title{
STUDI PENENTUAN DRAFT DAN LEBAR IDEAL KAPAL TERHADAP ALUR PELAYARAN (Studi Kasus: Alur Pelayaran Barat Surabaya)
}

\author{
Putu Angga Bujana, Yuwono \\ Jurusan Teknik Geomatika FTSP-ITS, Kampus ITS Sukolilo, Surabaya, 60111 \\ Email : anggabujana@yahoo.com
}

\begin{abstract}
Abstrak
Alur Pelayaran Barat Surabaya (APBS) merupakanalurpelayaran yang menghubungkankapal-kapal yang akan berlabuh di PelabuhanTanjung Perak dariLaut Utara Jawa. Seringnya lalu lintas kapal di daerah ini memerlukan penelitian mengenai pasang surut, topografi dasar laut, serta bobot kapal yang melintas untuk memastikan kapal-kapal yang akan berlabuh di Pelabuhan Tanjung Perak aman dari kemungkinan kecelakaan. Penelitian ini bertujuan untuk mengetahui keselamatan navigasi kapal yang akan berlabuh di Pelabuhan Tanjung Perakserta memberikan informasi mengenai draft dan lebar kapal yang ideal untuk melintas denga naman dalam keadaan tersurut di sepanjang Alur Pelayaran Barat Surabaya, serta kapal yang bias melintas dengan aman saat keadaan sarat muatan.

Hasil penelitian ini menunjukkan bahwa untuk kapal yang memiliki lebar sampai 15 meter bisa melintas dengan draft maksimal 6,2 meter dan kapal yang memiliki lebar maksimal 30 meter, bisa melintas dengan draft sebesar 5,5 meter. Semua draft tersebut sudah dihitung sampai keadaan Low Water Spring, serta kapal dengan bobot terbesar yang bisa lewat saat sarat muatan adalah jenis Kapal Penumpang dengan bobot 15.000 GRT.
\end{abstract}

Kata Kunci: APBS, Dermaga, Kapal, Navigasi

\section{PENDAHULUAN}

\section{Latar Belakang}

Pelabuhan Tanjung Perak memiliki peran strategis guna menunjang kegiatan lalu lintas transportasi angkutan laut dan sebagai penggerak pertumbuhan perekonomian. Setiap tahun pertumbuhan arus barang baik domestik maupun internasional, mengalami peningkatan melebihi kapasitas yang ada. Demikian juga dari tahun ketahun nilai pasang surut dan sedimen dasar laut selalu berubah [1].

Dermaga Jamrud Utara merupakan salah satu dermaga yang ada di Pelabuhan Tanjung Perak, dengan arus keluar masuk kapal yang cukup padat, karena merupakan dermaga internasional. Tercatat pada tahun 2011 ada 14.117 kapal berlabuh di Jamrud Utara, sedangkanpadatahun 2012 mengalamipeningkatanmenjadi 14.773 kapal, sumber data berasaldari data traffic kapal Pelabuhan Tanjung Perak. Semuakapal yang akan berlabuh di Pelabuhan Tanjung Perak harus melewati Alur Pelayaran Barat Surabaya (APBS).

Dengan mengetahui secarapasti data pasang surut, bobot kapal yang berlabuh, serta peta bathimetri yang memuat data kedalaman dasar laut alur pelayaran hingga kolam dermaga, makaakan didapat sebuah analisis dan kesimpulan mengenai ukuran kapal ideal yang bisa melintasi APBS dengan aman.

Diharapkan dapat memberikan manfaat berupa rekomendasi lebar dan draft kapal paling ideal untuk meminimalisir potensi kandasnya kapal, serta jenis kapal yang bias melintas dengan sarat muatan.

\section{Perumusan Masalah}

Perumusan masalah dalam penelitian ini adalah :

1. Bagaimanacara mengetahui draft dan lebar ideal kapal yang bisa melintasi APBS?

2. Bagaimana cara mengetahui jenis kapal yang bisa melintas dengan sarat muatan di APBS?

\section{METODOLOGI PENELITIAN}

\section{Lokasi Penelitian}

Lokasi penelitian tugas akhir ini adalah Alur Pelayaran Barat - Pelabuhan Tanjung Perak Surabaya, yang secara geografis terletak antara $6^{\circ} 50^{\prime} 00^{\prime \prime}$ LS - $7^{\circ} 15^{\prime} 00^{\prime \prime}$ LS dan $112^{\circ} 35^{\prime} 00^{\prime \prime}$ BT $112^{\circ} 45^{\prime} 00^{\prime \prime}$ BT. 


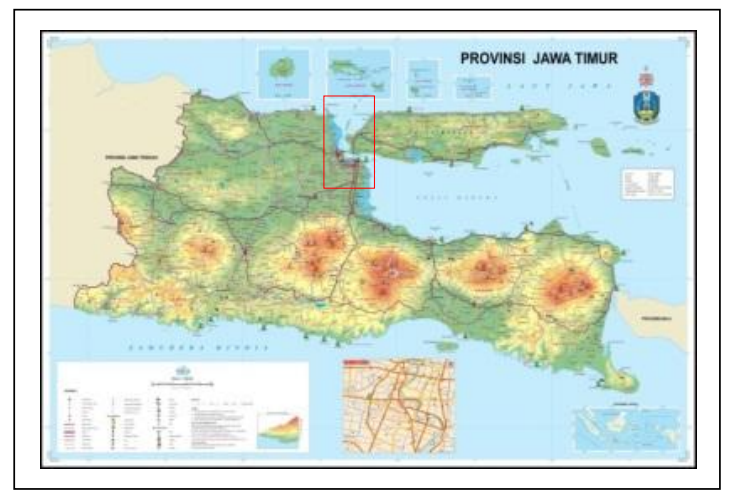

Gambar 1. Lokasi Penelitian

\section{Data dan Peralatan}

\section{- Data}

Data yang digunakan dalam penelitian ini adalah:

1. Peta Alur Pelayaran Barat Surabaya Tahun 2012.

2. Peta Pelabuhan Surabaya dan Gresik Tahun 2013.

3. Data Traffic Kapal Jamrud Utara PT. PELINDO III Tahun 2012.

4. Data Pasang Surut Prediksi Stasiun Karang Jamuang Tahun 2014.

5. Data Pasang Surut Prediksi Stasiun Tanjung Perak Tahun 2014.

- Peralatan

Peralatan yang digunakan dalam penelitian ini berupa perangkat keras 1 unit PC computer dan perangkat lunak pengolahan data spasial.

\section{Diagram Alir Pengolahan Data}

Penjelasan diagram alir tahapan pengolahan data pada gambar 2. tersebut adalah:

1. Transformasi Sistem Proyeksi

Dilakukan proses transformasi sistem proyeksi pada Peta Alur Pelayaran Barat Surabaya dan Peta Pelabuhan Surabaya dan Gresik. Tujuan proses transformasi sistem proyeksi ini adalah untuk mengubah sistem proyeksi peta yang menggunakan proyeksi Mercator menjadi proyeksi Universal Transverse Mercator. Proses transformasi antar sistem proyeksi menggunakan empat titik koordinat sebagai referensi transformasi.

2. Dijitasi Peta

Setelah peta mempunyai proyeksi UTM, maka tahap selanjutnya adalah dijitasi peta tersebut menjadi format peta garis. Peta ini digunakan sebagai peta dasar dalam penelitian ini.

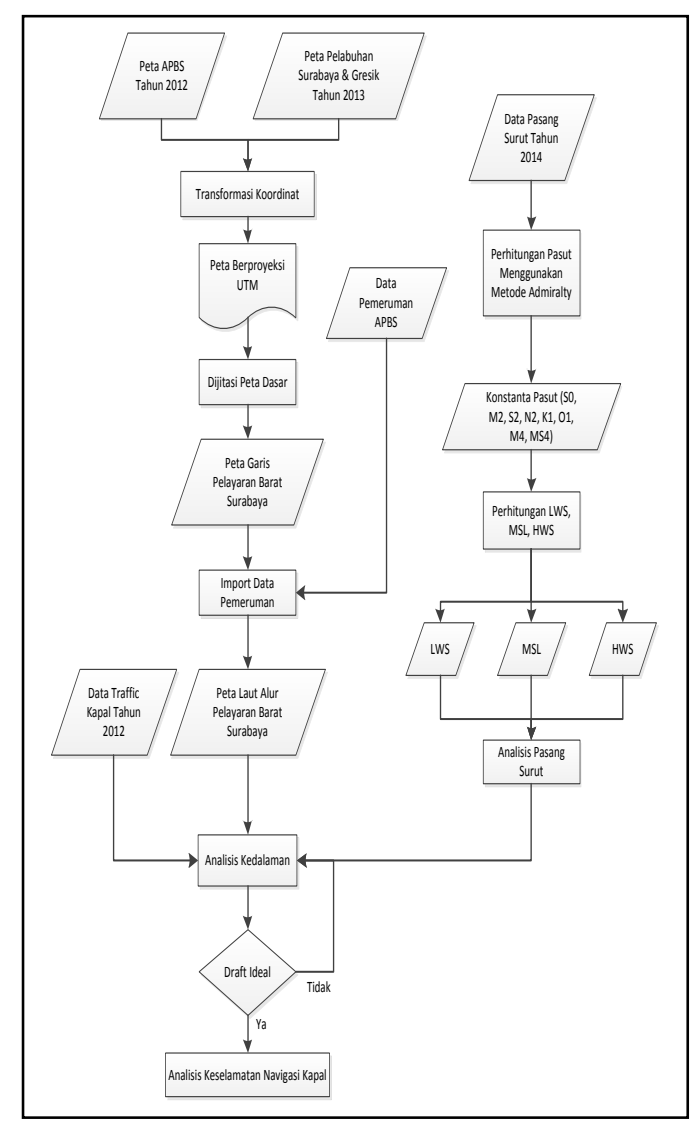

Gambar 2. Diagram Alir Tahapan Pengolahan Data

3. Import Data Pemeruman

Data pemeruman kemudian di-import ke dalam peta garis untuk menghasilkan peta bathimetri yang memiliki kedalaman laut. Dari peta bathimetri ini, dapat dihasilkan analisis terhadap kedalaman di sepanjang alur pelayaran.

4. Perhitungan Data Pasang Surut

Data pasang surut prediksi diolah menggunakan metode admiralty untuk mendapatkan komponen harmonik pasang surut. Komponen harmonik digunakan untuk menemukan Low Water Spring (LWS), Mean Sea Level (MSL), dan High Water Spring (HWS) di dua stasiun pengamatan, yaitu Tanjung Perak dan Karang Jamuang.

5. Analisis Pasang Surut

Setelah menemukan komponen harmonik pasut, dilakukan analisis jenis pasang surut dan analisis fluktuasi muka air.

6. Analisis Draft dan Lebar Ideal

Data traffic kapal digunakan untuk menganalisis draft kapal yang melintas. 
Analisis utamanya adalah menentukan kedalaman ideal bagi semua kapal yang akan melintasi APBS. Data LWS, MSL, dan HWS digunakan sebagai referensi kedalaman terendah sampai tertinggi bagi kapal yang akan melintas. Apabila belum menemukan kondisi dimensi ideal kapal yang akan melintas, maka analisis kembali dilakukan.

\section{HASIL DAN PEMBAHASAN}

Hasil dari proses pengolahan dan perhitungan adalah sebagai berikut:

\section{Pengolahan Data Cross Section APBS}

Peta bathimetri APBS diolah menjadi potongan melintang dengan jarak antar potongan 500 meter. Hal ini untuk memudahkan analisis bentuk dasar laut APBS. Karena penelitian ini menggunakan dua stasiun pasang surut, yaitu Karang Jamuang (APBS) dan Pelabuhan Perak, maka APBS dibagi menjadi 2 bagian. Section 1-46 menggunakan data pasang surut Karang Jamuang 2014 dan dari section 46-91 menggunakan data pasang surut Pelabuhan Perak. Analisis kedalaman disesuaikan dengan lokasi section. Pada Gambar 3 berikut adalah section yang memiliki elevasi terdangkal.

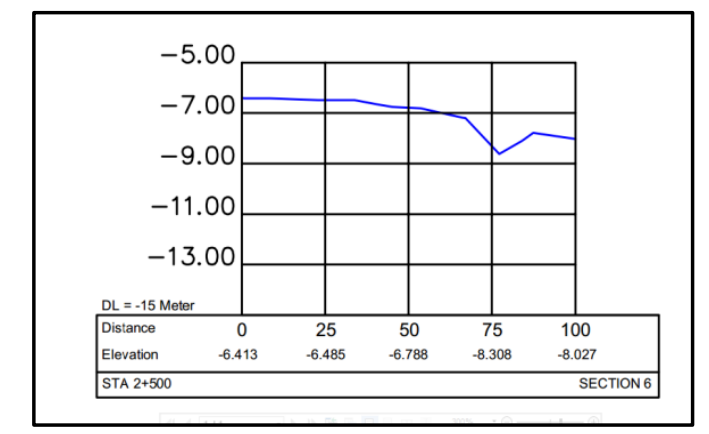

Gambar 3. Cross Section atau Potongan Melintang Nomor 6

Section 6, atau pada jarak 2,5 km dari pintu masuk alur pelayaran memiliki elevasi terendah, yaitu mencapai $-6,413$ meter yang menurun menjadi $-8,027$ meter, dengan elevasi beracuan pada Low Water Spring (LWS). Section 6 menggunakan data pasang surut Karang Jamuang sebagai referensi dinamika muka air, yang berfungsi sebagai acuan bobot kapal yang akan melintas.

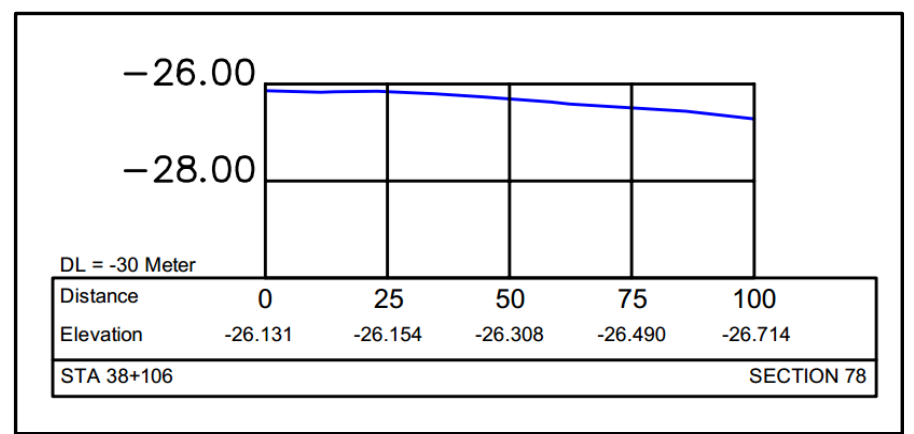

Gambar 4. Cross Section atau Potongan Melintang Nomor 78

Elevasi terdalam di APBS terdapat pada section 78 atau pada jarak 38,108 km dari pintu masuk alur. Bentuknya dapat dilihat pada Gambar 4. Section 78 menggunakan data pasang surut Pelabuhan Tanjung Perak sebagai referensi dinamika muka air laut dan sebagai referensi acuan bobot kapal yang dapat melintas.

2. Pengolahan Data Pasang Surut Tahun 2014

Data pasang surut tahun 2014 digunakan untuk referensi perubahan muka air laut, yang berguna untuk informasi elevasi tersurut air laut. Pengolahan data pasang surut menggunakan metode admiralty 29 piantan untuk mencari Low Water Spring (LWS), Mean Sea Level (MSL), dan High Water Spring (HWS). Pada Tabel 1 berikut ini adalah ratarata konstanta harmonik pasut Karang Jamuang tahun 2014.

Tabel 1. Komponen Harmonik Pasut Tahun 2014 Stasiun Karang Jamuang

\begin{tabular}{ccccccccc}
\hline Komponen & $\mathrm{S}_{0}$ & $\mathrm{M}_{2}$ & $\mathrm{~S}_{2}$ & $\mathrm{~N}_{2}$ & $\mathrm{~K}_{1}$ & $\mathrm{O}_{1}$ & $\mathrm{M}_{4}$ & $\mathrm{MS}_{4}$ \\
\hline $\begin{array}{c}\text { Amplitudo } \\
(\mathrm{cm})\end{array}$ & 110 & 5 & 8 & 1 & 55 & 26 & 1 & 1 \\
Fase $\left(^{\circ}\right)$ & & 14 & 233 & 171 & 315 & 253 & 191 & 132 \\
\hline
\end{tabular}

Berdasarkan komponen harmonik diatas, dapat dicari jenis pasang surut Karang Jamuang menggunakan rumus:

$\mathrm{F}=\left(\mathrm{O}_{1}+\mathrm{K}_{1} / \mathrm{M}_{2}+\mathrm{S}_{2}\right)$

$\mathrm{F}$ = Bilangan Formzahl

$\mathrm{O}_{1}=$ Amplitude komponen pasang surut tunggal utama yang disebabkan oleh gaya tarik bulan. 
$\mathrm{K}_{1}=$ Amplitudo komponen pasang surut tunggal utama yang disebabkan oleh gaya tarik matahari.

$M_{2}=$ Amplitudo komponen pasang surut ganda utama yang disebabkan oleh gaya tarik bulan.

$\mathrm{S}_{2}=$ Amplitudo komponen pasang surut ganda utama yang disebabkan oleh gaya tarik matahari.

Hasil perhitungan bilangan Formzahl pasut Karang Jamuang adalah sebesar 6,283 yang berarti tipe pasut Karang Jamuang adalah tunggal atau diurnal tide.Menurut Benyamin (2009), dan Rachmayanti (2009) untuk mencari LWS dan HWS, menggunakan rumus:

$\mathrm{MSL}=\mathrm{S}_{0}$

LWS $=\mathrm{S}_{0}-1,1\left(\mathrm{M}_{2}+\mathrm{S}_{2}\right)$

$\mathrm{HWS}=\mathrm{S}_{0}+\left(\mathrm{M}_{2}+\mathrm{S}_{2}+\mathrm{K}_{1}+\mathrm{O}_{1}\right)$

Dengan rumus tersebut, didapat hasil pada Tabel 2 berikut ini:

Tabel 2. Hasil Perhitungan LWS, MSL, dan HWS Karang Jamuang (meter)

\begin{tabular}{ccc}
\hline LWS & MSL & HWS \\
\hline 0,959 & 1,100 & 1,904 \\
\hline
\end{tabular}

Menggunakan metode admiralty 29 piantan, didapat perhitungan rata-rata komponen harmonik pasut Tanjung Perak tahun 2014 adalah pada Tabel 3 berikut.

Tabel 3. Komponen Harmonik Pasut Tahun 2014 Stasiun Tanjung Perak

\begin{tabular}{ccccccccc}
\hline Komponen & S0 & M2 & S2 & N2 & K1 & O1 & M4 & MS4 \\
\hline $\begin{array}{c}\text { Amplitude } \\
(\mathrm{cm})\end{array}$ & 150 & 44 & 26 & 9 & 47 & 28 & 0 & 0 \\
\begin{tabular}{c} 
Fase $\left(^{\circ}\right)$ \\
\hline
\end{tabular} & 322 & 340 & 303 & 293 & 265 & 220 & 217 \\
\hline
\end{tabular}

Hasil perhitungan bilangan Formzahl komponen harmonik pasut Tanjung Perakmenggunakan rumus (1) mendapat hasil sebesar 1,075, yang berarti tipe pasang surut Tanjung Perak adalah campuran condong ke harian ganda (mixed tide prevailling semi diurnal). Perhitungan LWS, MSL, dan HWS Tanjung Perak menggunakan rumus (2), (3), dan (4) memperoleh hasil pada Tabel 4 berikut.
Tabel 4. Hasil Perhitungan LWS, MSL, dan HWS Tanjung Perak (meter)

\begin{tabular}{ccc}
\hline LWS & MSL & HWS \\
\hline 0,733 & 1,500 & 2,250 \\
\hline
\end{tabular}

\section{Perhitungan Bobot Serta Draft Ideal Kapal I}

Draft kapal yang melintasi APBS dihitung dari tabel klasifikasi kapal[5] menggunakan data bobot kapal. Tabel 5 berikut adalah 5 bobot kapal terbesar yang pernah melintasi APBS pada tahun 2012 beserta draft-nya.

Tabel 5. Draft Kapal 2012

\begin{tabular}{lcc}
\hline \multicolumn{1}{c}{ NAMA } & DWT (TON) & DRAFT $(\mathrm{m})$ \\
\hline WHITE TOKIO, MV & 11.1342 & 15,231 \\
CMB PAUILLAC, MV & 95.707 & 14,585 \\
BOTTIGLIERI GIULIO & 93.273 & 14,464 \\
ORRIELLO & 93.025 & 14,451 \\
OCEAN DIAMOND , MV & 92.500 & 14,425 \\
CLIA , MV & \\
\hline
\end{tabular}

Draft kapal terbesar yang pernah melewati APBS adalah sebesar 15,231 meter. Untuk keperluan keselamatan pelayaran, digunakan rumus:

$H=d+G+R$

$\mathrm{H}=$ kedalaman total air di alur pelayaran saat muka air terendah (m)

$\mathrm{G}=$ gerakan vertika lkapal karena

$\frac{B}{2} \times \sin \alpha$

$\alpha=$ sudut oleng kapal (diambil 5ㅇ)

$B=$ lebar kapal $(\mathrm{m})$

R: Ruang kebebasan bersih (m) (clearance) sebagai pengaman antara lunas dengan dasar laut (pantai pasir $=0,5 \mathrm{~m}$ )

Maka didapat kedalaman minimal yang harus dimiliki alur pelayaran adalah 16,568 meter saat keadaan air tersurut (LWS) agar kapal MV. WHITE TOKIO bisa lewat dengan aman dalam keadaan sarat muatan. Sedangkan kedalaman total air APBS saat keadaan tersurut adalah:

Kedalaman $=$ LWS + Kedalaman Terendah

Kedalaman total air di APBS pada bagian yang terdangkal di section 6 sebesar 7,372 meter. Dari perhitungan di atas, APBS tidak ideal untuk dilewati kapal berbobot besar dengan kapasitas 
sarat muatan. Agar kapal bisa melewati APBS, maka harus mengurangi muatannya dahulu. Kapal yang bisa melewati APBS dengan keadaan muatan penuh dihitung menggunakan rumus (5) dan tabel klasifikasi kapal, sampai pada keadaan tersurut adalah kapal berikut (Tabel 6).

\section{Tabel 6. Kapal Yang Bisa Lewat Dengan Bobot} Maksimal

\begin{tabular}{cccc}
\hline JENIS KAPAL & BOBOT MAKSIMAL & DRAFT $(\mathrm{m})$ & LEBAR $(\mathrm{m})$ \\
\hline KapalPenumpang & $15.000 \mathrm{GRT}$ & 5,6 & 22,5 \\
KapalBarangUmum & $5.000 \mathrm{DWT}$ & 6,1 & 16 \\
Kapal Ferry & $10.000 \mathrm{DWT}$ & 5,3 & 22,6 \\
KapalRoro & $5.000 \mathrm{DWT}$ & 5,8 & 19,5 \\
Kapal Tanker & $5.000 \mathrm{DWT}$ & 6,1 & 16 \\
\hline
\end{tabular}

Untuk kapal lain yang akan berlabuh, dapat dihitung draft idealnya dari LWS Karang Jamuang dan lebar kapal tersebut menggunakan rumus (5) dan Tabel 2. Berikut adalah hasil perhitungan draft dan lebar kapal maksimal yang bisa melewati APBS pada keadaan tersurut (Tabel 7).

Tabel 7. Daftar Kapal Yang Bisa Lewat Dengan Spesifikasi Draft Dan Lebar Saat LWS

\begin{tabular}{|c|c|c|c|c|c|}
\hline \multicolumn{3}{|c|}{ Kedalaman Alur Saat (meter) } & \multicolumn{2}{|c|}{$\begin{array}{l}\text { Draft Maksimal } \\
\qquad(\mathrm{m})\end{array}$} & \multirow{2}{*}{$\begin{array}{c}\text { Lebar } \\
\text { Maksimal } \\
\text { (m) }\end{array}$} \\
\hline LWS & MSL & HWS & LWS & HWS & \\
\hline 7,372 & 7,513 & 8,317 & 6,1 & 7,1 & 15 \\
\hline 7,372 & 7,513 & 8,317 & 6 & 6,9 & 20 \\
\hline 7,372 & 7,513 & 8,317 & 5,7 & 6,7 & 25 \\
\hline 7,372 & 7,513 & 8,317 & 5,5 & 6,5 & 30 \\
\hline
\end{tabular}

\section{PENUTUP}

Berdasarkan hasil penelitian mengenai analisis keselamatan navigasi kapal, didapat kesimpulan antara lain:

1. Kapal yang akan melintasi APBS, disarankan memiliki draft maksimal 6,1 meter saat LWS dan 7,1 meter saat HWS untuk lebar maksimal 15 meter. Untuk kapal yang memiliki lebar20 meter, hanya boleh maksimal memiliki draft 6 meter saat LWS, dan 6,9 meter saat HWS. Kapal dengan lebar 25 meter, maksimal memiliki draft 5,7 meter saat LWS dan 6,7 meter saat HWS, kapal dengan lebar maksimal 30 meter, wajib memiliki draft maksimal 5,5 meter saat LWS dan 6,5 meter saat HWS.
2. Kapal yang boleh melintasi APBS dengan sarat muatan pada keadaan surut terendah adalah Kapal Penumpang berbobot maksimal 15.000 GRT, Kapal Barang Umum berbobot maksimal 5.000 DWT, Kapal Ferry berbobot maksimal 10.000 DWT, Kapal RORO berbobot maksimal 5.000 DWT, dan Kapal Tanker berbobot maksimal 5.000 DWT.

3. Saran dari penelitian ini adalah agar data fitur dasar laut memiliki sumber yang lebih valid lagi, sehingga bisa memberikan informasi yang lebih jelas.

\section{DAFTAR PUSTAKA}

Bujana, P. A., \& Syahputra, R. A. 2013. Analisis Kesesuaian Dimensi Kapal Terhadap Kolam Dermaga Jamrud Utara Pelabuhan Tanjung Perak Surabaya. Surabaya: Jurusan Teknik Geomatika.

Hidayat, $\quad$ S. 2010. AnalisisHarmonikPasangSurutMenggunaka nMetode Admiralty (StudiKasus: PelabuhanBeras, Bontang, KalimantanTimur). Bogor: InstitutPertanian Bogor.

Benyamin, A. J. 2009. Penentuan Chart Datum Dengan Menggunakan Komponen Pasut Untuk Penentuan Kedalaman Kolam Dermaga. Surabaya: Program Studi Teknik Geomatika.

Rachmayanti, I. A. 2009. Penentuan High Water Spring (HWS) Dengan Menggunakan Komponen Pasut Untuk Penentuan Elevasi Dermaga (Studi Kasus: Rencana Pelabuhan Teluk Lamong). Surabaya: Program Studi Teknik Geomatika.

Triatmodjo, B. 2009. Perencanaan Pelabuhan. Yogyakarta: Beta Offset. 


\section{LAMPIRAN}

Peta Cross Section 1-91 APBS

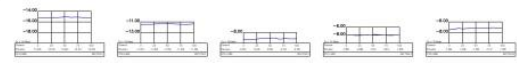
\# 3 3.1

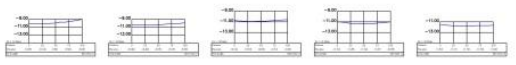

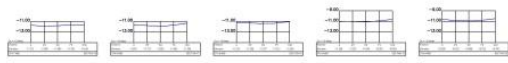

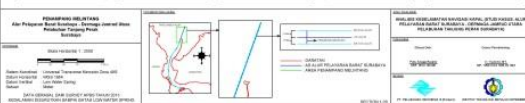

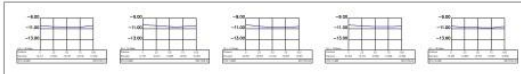
\#\# \#\# \#\# \# \# \#\# \#\# \#\#

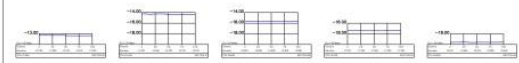

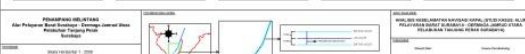

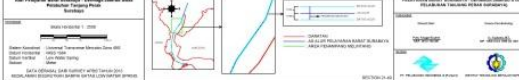

표 \#政

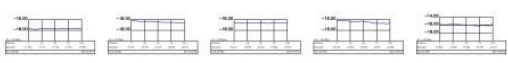

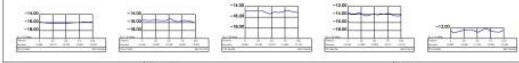

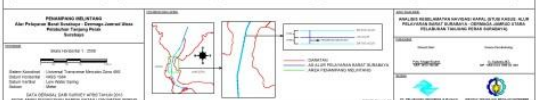

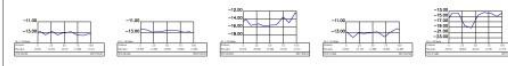

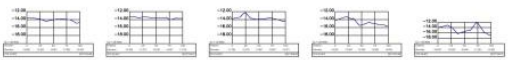

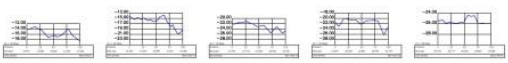
패

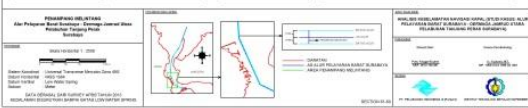

0
$=-1$ 